\title{
A Importância da Carta de Feições Morfológicas e Hidrográficas em Trabalhos Ambientais: estudo de caso em São Luís-MA.
}

\author{
Jorge Hamilton S. dos Santos \\ UFMA- Universidade Federal do Maranhão \\ Departamento de Geociências - Av. Portugueses S/N \\ Campus Universitário do Bacanga São Luís - MA \\ CEP: 65080-040 Fone: (098)217-8330
}

\begin{abstract}
The main objective of the present work was to describe the importance of the utilization of the morphological and hydrographical features chart on environmental studies. The coastal fringe of the northem part of the city of São Luís, MA, was analysed on geoprocessing basis. The confection of eigth(8) charts in 1:8.000 scale, allowed the elaboration of signatures, monitoring and assessment that permited the production of satisfactory forecasts. The creation of data base composed of potential urbanization and touristic development maps together with respective pressure and conflicts on areas of environmental protection were provided.
\end{abstract}

Keywords: Enviromental Studies, Coastal Fringe, Goprocessing.

\section{Introdução}

A preocupação mundial com os problemas ambientais tem se tornado cada vez maior, uma vez que os modelos adotados de utilização do espaço geográfico, nas últimas décadas, vêm-se caracterizando por uma diminuição da qualidade de vida, em consequência da degradação dos ecossistemas existentes.

Na franja costeira ao Norte da cidade de São Luís, existe uma grande diversidade de ecossistemas, tais como os que estão presentes em estuários, lagoas, cursos fluviais, maguezais, tabuleiros, dunas costeiras, praias, os quais apresentam especificidades floristicas e faunisticas associadas a sua origem, porém constantemente descaracterizadas, em função da instalação de novas edificações, loteamentos, empreendimentos turísticos, assim como pela ampliação da malha viária. Logo, tais práticas tendem, num futuro próximo, a inviabilizar não só a dinâmica desse ambiente como também as atividades voltadas ao Turismo e Lazer, SANTOS (1993/94).

Devido a gravidade dessas alterações na orla marítima compreendida pelas praias da Ponta d'Areia, São Marcos, Calhau e Parte do Olho d'Água, realizouse uma análise da ocupação da área fundamentada com base no geoprocessamento, na qual pôde-se determinar os potenciais de urbanização e empreendimentos turísticos, bem como as áreas com necessidade de proteção.

$\mathrm{Na}$ concretização deste estudo as cartas das feições morfológicas e hidrográficas apresentam-se de fundamental importância, tanto na determinação dos potenciais anteriormente citados, e no monitoramento dos recursos naturais, quanto na confecção da carta de necessidade de proteção como será demonstrado no decorrer do texto.

\section{Localização da Área de Estudo}

A área em tela localiza-se ao Norte da cidade de São Luís, sede da Capital do Estado do Maranhão, compreendendo a franja costeira da Ponta d'Areia, São Marcos, Calhau e parte do Olho d'Água, com aproximadamente $11 \mathrm{~km}$ de extensão e delimitada pelas coordenadas geográficas: $2^{\circ} 29^{\prime \prime}$ e $2^{\circ} 30^{\prime \prime}$ Lat. Sul; $44^{\circ}$ 14 'e $44^{\circ} 19^{\prime \prime}$ Long. Oeste. (Fig. 1)

\section{Metodologia}

Os procedimentos adotados para a execução deste trabalho foram os seguintes:

Seleção e Consulta da bibliografia;

delimitação da área em estudo em função dos problemas existentes, bem como pela disponibilidade de documentação cartográfica e levantamentos aerofotogramétricos em escala de detalhe;

elaboração de cartas temáticas (uso e cobertura do solo, feições morfológicas e hidrográficas e hipsométrica) a partir da interpretação de 45 fotografias aéreas de 1988 e 1993 em escala de 1:8.000 e 1:5.000 respectivamente;

confecção das cartas temáticas de proximidade e de necessidade de proteção a partir de técnicas de geoprocessamento

saidas a campo para obtenção de "verdades terrestres"onde procedeu-se o cortejo da realidade com modelo digital elaborado;

realização das etapas de pré-processamento tais como: compatibilização de escalas da base cartográfica, 
georeferenciamento dos planos de informação pelo sistema (coordenadas quilométricas), modulação para captura, escolha da resolução utilizada (75 DPI's) e vistoria da base de dados a fim de levantar algumas incongruëncia existente;

posteriormente utilizou-se a metodologia de pesquisa ambiental do SAGA/UFRJ, desenvolvido pelo Laboratório de Geoprocessamento do Departamento de Geografia da UFRJ, visando a utilização do inventário dos dados básicos disponiveis, sobre os quais foram executados as planimetrias, assinaturas, monitorias, avaliação e estimativas de impactos de acordo com XAVIER DA SILVA e CARVALHO FILHO (1993).

\section{Resultados e Discussōes}

As cartas das feições morfológicas possibilitaram a identificação das principais feições caracteristicas do local de estudo, nos anos de 1988 e 1993, a saber: praia, pós-praia, planície de inundação, planura antropizada, margens lacustre, falésia, planície de maré, dunas atuais e paleodunas, tabuleiros, voçorocas, lagoa, cursos d'água, encostas, superfície dissecada, relevo residual ondulado, corte antrópico e aterros.

A partir desses cartogramas digitais pode-se proceder as planimetrias, assinaturas e monitorias das características ambientais julgadas relevantes na área $\mathrm{e}$ sua respectiva quantificação. No tocante as assinaturas a referida carta foi de suma importância na definiçào de conjuntos de caracteristicas ambientais que estão locacionalmente associadas e um evento de interesse. Já as monitorias (simples e complexas) permitiram a constatação de alterações de localização e extensão das principais feições morfológicas ao longo do tempo. (Tab. 1)

A monitoria simples permite definir: I) os locais que não sofreram alteração; II) os locais ou de uma determinada característica passou a existir; III) os locais onde uma determinada características deixou de existir e IV) os locais onde a características não existia na primeira ocasião e continua sem existir na segunda. Já a monitoria múltipla permitem inferencias de maior envergadura quanto à espacialidade e temporalidade inerentes aos fenômenos ambientais, pois, uma vez definidas as áreas, que uma característica deixou de existir (Item III acima) e os locais onde uma caracteristica passou a existir (Item II) torna-se possivel a obtenção das seguintes informações:

- o destino dado a área que sofreu alteração;

- em que características ambientais veio incidir uma determinada expansão territorial.

$\mathrm{Na}$ área em tela as citadas monitorias revelaram-se bastante informativa, pois permitiram acompanhar as alterações ocorridas na lagoa da Jansen, dunas atuais, paleodunas, praia, encostas e demais feições morfológicas, além dos diversos estratos vegetais (vegetação herbácea, arbustiva, arbórea) existentes.
A avaliação baseia-se na atribuição de pesos e notas aos planos de informações (cartas temáticas) e suas respectivas classes (legendas) usando-se as informações dos procedimentos disgnósticos, tais como planimetrias, assinaturas e monitorias, além do conhecimento do evento de interesse da área investigada. Os pesos atribuidos pelo usuário a cada carta temática previamente selecionada dizem respeito a sua participação relativa, em relação as demais cartas, para ocorrência do fenômeno em pauta. Nesta etapa é mandatório que o somatório dos pesos feche em 1 ou seja $100 \%$. As notas dadas as classes de cada carta referem-se à possibilidade de associação da respectiva classe com o fenômeno estudado. Estas notas podem variar de zero a dez ou de zero a cem de acordo com os objetivos propostos e a necessidade de refinamento da classificação.

Quando do processo avaliativo para a determinação do potencial de urbanizaçào constatou-se que algumas variáveis se destacaram sobre as demais. Logo, o peso atribuido as feições morfológicas e hidrográficas foi de $35 \%$, por terem se apresentado como forte definidora do processo espacial de urbanização enquanto que as cartas de proximidades de vias de acesso e praia, uso e cobertura do solo e hipsometria foi definido o peso de $30 \%, 20 \%$ e $15 \%$ respectivamente.

Com relação ao potencial para empreendimentos turísticos, além dos aspectos morfológicos e da estrutura viária, algumas classes hipsométricas e de uso e cobertura do solo apresentaram-se como significativas na determinação do mesmo. Logo, os pesos atribuidos a cada um dos 4 (quatro) parâmetros foi de $25 \%$.

Com os pesos devidamente estabelecidos, procedeu-se à valorização das legendas constantes dos respectivos planos de informação, onde as notas variaram de 0 a 10 , de acordo com sua possibilidade territorial com o evento de interesse, o que tornou possivel a elaboração das cartas com os respectivos potenciais anteriormente citados.

Ainda com referencia ao cartograma digital das feições morfológicas e hidrográficas, este permitiu a confecção da carta de necessidade de proteção conforme o Código Florestal Lei $n^{\circ} 7.803$, citado por TOSTES (1994) e pela Lei do Plano Diretor de São Luis, as quais definem as faixas marginais das áreas de preservação permanente da vegetação ao entorno dos cursos fluviais, das nascentes e ao redor dos reservatórios d'água. Os demais elementos naturais presentes no local (lagoa, manguezais, dunas, paleodunas e cursos d'água) considerados de preservação permanente foram mapeados a partir da sua área de ocorrência.

Em sintese este plano de informação, foi gerado através do SAGA/UFRJ, objetivando realizar o cotejo com os resultados das avaliações diretas (potenciais de urbanização e empreendimento turístico), para se 
determinar as pressões oriundas dos referidos potenciais, sobre as áreas protegidas por Lei as quais foram perfeitamente mapeadas nesta investigação em escala de detalhe $(1: 8.000)$.

\section{Considerações Finais}

Como se observa, a utilização de cartas das feições morfológicas e hidrográficas podem fornecer informações fundamentais em estudos geoambientais, sendo estes de efetiva aplicabilidade a gestão de uso do solo e da melhoria da qualidade ambiental em diferentes espaços geográficos.

\section{Referências Bibliográficas}

SANTOS, J.H.S. dos Levantamento preliminar dos problemas ambientais de uma zona Litorânea de São Luís-MA: UFMA, 1993, 81p. Monografia de especialização.

Avaliação preliminar dos principais impactos da zona costeira da cidade de São LuísMA. In: ENCONTRO BRASILEIRO DE CIÊNCIAS AMBIENTAIS, 1., Rio de Janeiro: UFRJ. Anais... 1994, v.3, p.1050-52.

TOSTES, A. Sistema de Legislação ambiental. Petrópolis: Vozes, 1994, 230p.

XAVIER DA SILVA, J. e CARVALHO FILHO, L.M.de. Análise ambiental por geoprocessamento: uma proposta metodológica. In: Conferência Latino Americana sobre sistemas de informação geográfica, 4., SIMPÓSIO BRASILEIRO DE GEOPROCESSAMENTO, 2., São Paulo: USP. Anais ... 1993, p.609-628. 


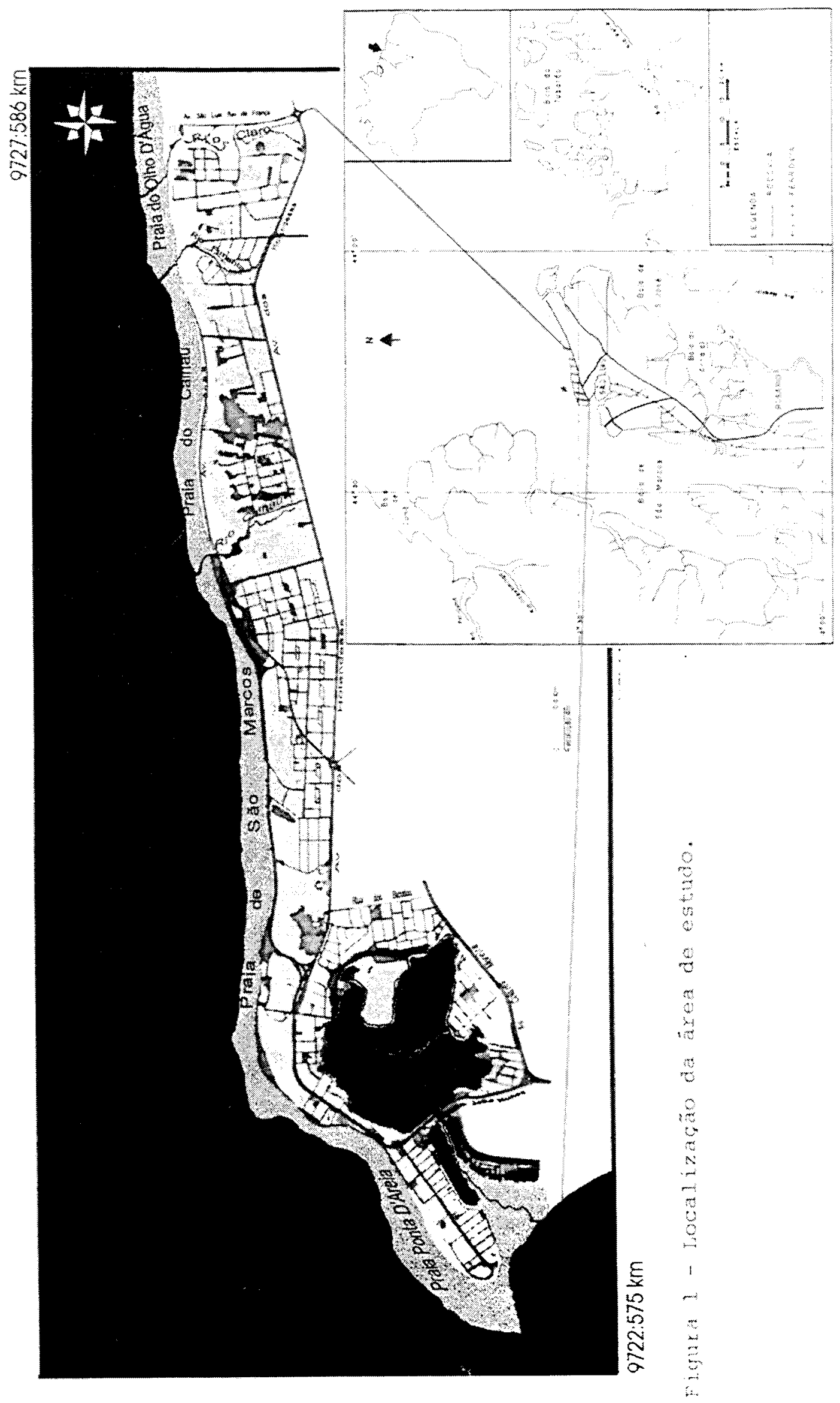


MONITORIA SIMPLES

$(1988 \times 1993)$

\begin{tabular}{|c|c|c|}
\hline & ha & $\%$ \\
\hline Deixou de ser Lagoa da Jansen & 7.42 & 5.51 \\
\hline Tornou-sc Lagoa da Jansen & 1.46 & 1.08 \\
\hline Permancecu lagoa da Jansen & 125.83 & 93.41 \\
\hline
\end{tabular}

MONITORIA MÚLTIPLA (Deixou de ser Lagoa e tornou-se:)

$(1988 \times 1993)$

\begin{tabular}{|c|c|c|}
\hline & ha & $\%$ \\
\hline Estrada cm construção $\mathrm{cm}$ torno da lagoa & 0.21 & 2.83 \\
\hline Edilicação de médio/alio padrão & 0.01 & 0.13 \\
\hline Edilicação de baixo padrão & 0.39 & 5.26 \\
\hline Palalita & 0.65 & 8.76 \\
\hline Vcgetação herbácea & 0.80 & 10.78 \\
\hline Vegelação arbustiva & 0.01 & 0.13 \\
\hline Manguc & 0.65 & 8.76 \\
\hline Solo desnudo & 2.01 & 27.22 \\
\hline l ama & 2.68 & 36.12 \\
\hline
\end{tabular}

MONITORIA MÚLTIPLA (Tornou-se Lagoa sobre as seguintes características:)

(1988 $\times 1993)$

\begin{tabular}{|l|c|c|}
\hline Manguc & 0.48 & 32.88 \\
\hline Vegctação herbácea & 0.03 & 2.05 \\
\hline Solo desnudo & 0.12 & 8.22 \\
\hline Palalitas & 0.83 & 56.85 \\
\hline
\end{tabular}

Tabcla 1 - Resultados das monitorias simples c múltipla da Lagoa da Jansen da franja costcira de São Luis - MA, no periodo de 1988 a 1993. 